\title{
Research on the Marketing Strategy of the Clothing Store in the Era of Electronic Commerce
}

\author{
Yachang Wang \\ Huanghe Science and Techology College \\ Zhengzhou, Henan, China 450046
}

\begin{abstract}
Traditional clothing sales model has been strongly impacted by the persistent overheating trend of the electronic commerce. In order to cope with the great change of this marketing model, many clothing enterprises have also joined the trend of the network businessman, and try to dominate the situation. This paper starts the research from three aspects. First of all, analyze the typical advantages of ecommerce marketing; second, do a comparison between the ecommerce marketing mode and the store marketing mode, and seek the disadvantages of the store marketing mode; finally, find the solution to drawbacks of the store marketing mode. It is aimed to change the store retail mode, to adapt to changes in the environment, and reach the highest benefit.
\end{abstract}

Keywords-e-commerce; clothing; store; marketing New characteristics of Chinese graphic design

\section{INTRODUCTION}

At present, the human society has stepped into a new stage of development - the Internet age. People of all ages and both sexes are enjoying the convenience of online shopping in our daily life. For the clothing industry, the strength of the network sales is particularly strong, and it has become the most important clothing sales channel at present. Accordingly, with the advent of the digital era, the e-commerce is also a strong impact on the marketing model of traditional industrial society. In this paper, the author has made a detail research and analysis on the current situation of the store sales and the network sales of clothing industry. Through the comparison, sort out the advantages and disadvantages of store sales and network sales and positively solve marketing problems of store managers.

\section{THE GENERAL DEVELOPMENT SITUATION OF ELECT RONIC COMMERCE IN CLOTHING INDUSTRY}

Since the appearance of electronic commerce in 1997 , the network marketing has experienced the stages of exploration, promotion and development and maturity. At present, the electronic commerce is still in the golden period. The electronic commerce of the domestic clothing industry rises gradually with the times advancement. In the last few years, the clothing network sale ability is more powerful. Due to the low threshold, not limited by region, a large number of businessmen with first-hand source of goods begin to use the platform of network to sell clothing at a low price. And there are many varieties. It meets a wide range of people's consumption psychology. The network market has gradually entered into a mature stage. Many marketers use their cost advantage to gain a foothold in the network platform.

\section{A. E-commerce marketing model of the clothing industry}

Electronic commerce in clothing industry is rising and booming. It can effectively reduce the cost of sales, improve the efficiency of the transaction, and increase the number of transactions.

In the industry, the electronic commerce in clothing industry is divided into four kinds of marketing model. The first is the interaction transaction mode between supply and demand, which is to simplify the business process. The network, as a channel, facilitates enterprises to deliver and receive information, order goods, receive and deliver files and arrange logistics. The second is the online shop model. This marketing model provides a new type of shopping place that enterprises create through network platform, which puts products together, and provides consumers a relaxed shopping environment, saving consumers' time for daily work and life. The third is the internet auction model that sellers offer a price and buyers buy products in a bidding way through digital platform. The last is the clothing products sales agent model. Compared with the former three models, its target positioning is different. It is a means of distribution in order to promote sales.

\section{B. The application advantages and disadvantages of electronic commerce in the clothing industry}

The competition of clothing sales is always around the product's production, quality and cost, and the network provides such a good platform for marketers:

First, clothing manufacturers can use the electronic platform to strengthen the management system and to seek profitable source of goods, thereby reduce production and management costs, increase profits, and create more surplus value. By contrast, enterprises use network technology to reduce the cost of management and supply, and gain a higher rate of returns on investment.

Second, the popularity of clothing determines the fast pace of production and marketing. The means of ecommerce facilitates clothing manufacturers to grasp the market, for manufacturers can receive guests' feedback and 
collect relevant information at the fastest speed. Thus they can produce products that meet the needs of consumers.

Third, the transmission of electronic commerce information has no geographical restriction. People in any country and region, can communicate with each other with network equipment, and obtain firsthand information. The impact of digital technology makes a great change in the operation of our economic market. This has become a strong operational means for the production market of clothing industry.

Fourth, the online shopping experience has met the current consumer's life rhythm and psychological needs. The most important point is the price competition. The prices of network products are transparent. People can clearly compare, without worrying about the fairness of price.

Fifth, the network platform has low threshold, and is easy to get started, which provide many favorable conditions for businessmen with firsthand source of products to join in ecommerce tide.

But at the same time, the network clothing marketing also has its obvious disadvantages. For example, there are problems on try-on, after-sale service, logistic safety, online payment security and integrity. Although, network dealers are trying to change the current situation and strengthen sales service, these problems still exist, and can`t be ignored.

\section{The e-commerce development trend in the future clothing industry}

With the formation of consumers' online shopping habits, more and more people will choose to buy clothing through the internet. A large number of clothing enterprises and branded companies have begun to get involved in the field of e-commerce, so that consumers have more choices space. It also undoubtedly will lead to a sustained growth in the size of online shopping of clothing. Therefore, clothing ecommerce in the future will maintain the rapid growth trend. However, with the increasing market competition, the ecommerce marketing mode will become more and more diversified and personalized, so as to meet the personalized needs of users.

\section{THE ST ATUS ANALYSIS OF THE ClOTHING STORE MARKETING MODEL}

Influenced by the development of science and technology, the human life style is constantly enriched and shows a trend of diversification. But no matter how the consumer's life changes, it can't change the basic consumer demands: high performance cost ratio and to buy the best product at the most affordable price. And the current online shopping experience is catering to the consumer's basic psychology. The online trading volume is surpassing that of store gradually.

\section{A. The current situation of China's clothing store marketing}

Under the influence of the global economy, the Chinese economy has received a severe challenge since 2008.
Compared with the international situation, the import and export clothing trade transaction rate is declining, but the transaction rate shows a growing trend in the domestic clothing retail market.

In the future, China's clothing industry will face more challenges in the development: on the one hand, the export trade market is still tightening influenced by the international environment; on the other hand, the domestic employment pressure continues to increase, and the growth of labor income is difficult. At the same time, by the impact of the appreciation of raw materials in global trade, prices continue to rise, and the pressure of clothing sales is growing.

\section{B. The influence of the clothing e-commerce marketing on the clothing store marketing}

Clothing store marketing is a traditional model, while the e-commence marketing is a newly-developing model. At present, the online shopping volume is still rising. The network is becoming an important part of Chinese people's life. The influence of e-commerce marketing on the clothing store marketing is very obvious:

The first is the restriction of the sale of clothing store. The sales cost of traditional store is relatively high, such as store cost, management cost, and employment cost for service staff. In addition to operators, consumers are also consuming time. This is the reason why more and more people are obsessed with online shopping in the fast life pace.

The second is the low threshold of e-commerce which gives a majority of businessmen with firsthand source of products opportunity to open online shop. It has enhanced the price competitive advantage. These products have the advantage of short distance between production and consumption, reducing the commercial operation of many intermed iate businessmen. In this model, operators can gain high profit and consumers can pay relative low price, which promote the year-on-year increase on e-commerce operators and online consumers.

Then is the fast update speed of network information which meets the consumer's pursuit of new things. At same time, there are various info tips if there is product update in online shop. Consumers are able to grasp firsthand information without going outside, and it strengthens the customers' loyalty to the shop.

Finally is the continuous innovation of network marketing model which strengthens the security of online shopping platform. People's desire to buy is also gradually increasing. This feature is especially dominant in relative older people who have little knowledge of network techniques. Even if they can't use network, they are also willing to get help from young people to enjoy the convenience of electronic commerce for life. Young Internet users are driving the older consumers to shop online together with them, so that the online shopping is more and more powerful. 


\section{ThE STRATEGy ANALYSIS OF ClOT HING STORE MARKETING MODEL IN E-COMMERCE AGE}

Under the pressure of e-commerce, it is necessary to make a big reform on the traditional store marketing model in the future development process. The clothing of same quality with bad service will be abandoned by consumers gradually, while good service will be accepted and recognized by consumers.

In order to face such a huge challenge, the enterprises and the store dealers needs to make adjustments on product structure and channels and service mode, so as to transform disadvantages into advantages.

\section{A. Collecting flow information}

The operation of store clothing sales shall rely on a sound management mechanism. The survey data of various items shall be collected to analyze future sales strategy. Do not blindly make a decision without reference data, or consume energy and financial resources on non-purpose reform.

The data collected by the store shall be directly from the consumers, for it can directly reflect the customer's consumption purpose and consumption ability. The sufficient data is more conducive to the adjustment of marketing mode.

First of all, operators can `t ignore the consumer's implicit data. Analyze and find out hot sales of current period according to the consumer's shopping preferences, and find out the reason of hot sales, and thus adjust the operation means of the next quarter or the next stage.

Second, analyze and find out the reason why consumers do not buy these clothes while they buy others, and why they give up the purchase, thus determine the late sales strategy of such clothing.

Next, do after-sale service and make data statistics on regular customers. In gradually mature clothing consumption field, clothing store operators need to establish a long-term good relationship with customers. Through this kind of contact, customers may have new information and enjoy the information service in first time and feel respected. At same time, operators can provide customers with personalized service to save customers' purchasing time.

Then, develop a competition awareness between peers. Master to the opponent's sales information, in order to compare with own sales results, to find out the advantages and disadvantages of each other. In addition to giving same benefits and services to customers, operators shall be able to adjust the operation and management mode of the next phase according to these data.

The last is the collection of environmental information to know the flow of customers. According to the survey results, find out the problems of own brand currently and solve them purposely.

\section{B. Shortening the distance between consumers and products}

In order to do a good job in brand construction, the most important marketing strategy for clothing enterprises is to shorten the distance between consumers and products. In this way establish the image of the brand in the minds of consumers.

In addition to the image project, the most fatal factor is the price of clothing products in the competition between store marketing and e-commerce marketing. There are many intermediate links between product manufacturers and consumers in circulation process. However, the intermediate process directly affects the final cost of product. Therefore, it can directly save clothing cost to effectively reduce participation of intermediate brokers. In this way, operators can be in an invincible position in price competition, and thus shorten the distance between consumers and products.

\section{Being sure not to fight with online sales over price}

Although we shorten the distance between consumers and products, have fewer intermediate links and save costs as far as possible, the store is always unable to compete with online shop over price due to the costs of store rent, decoration, service and etc. Brutal price tactics can only make the operation of store worse, and can`t really solve the problems. The store still shall enhance the strength on brand promotion, provide consumers with a comprehensive service, research consumer's psychology and demands, so as to provide personalized service. Make innovations among advantages and defects, do not fight blindly, so that they can survive and develop better, and race with e-commerce to seize market share in a healthy way.

\section{Optimizing the shopping environment and promoting visual marketing}

The terminal image of clothing brand relies on the facade of store. The existing consumption characteristics tell us that the shopping environment suitable for the style of products can effectively improve the value of the product. This is related to the order of the customer's consumption. When consumers enter the store, the first is to see the display of the window. The clothing collocation in display window can directly stimulate consumer desire to buy. It may award marks for the clothing if the indoor environment is coordinated with the style of clothing collocation. Through many high-end brand store design, we can see that a good consumer environ ment is also involved in the added value of this clothing.

For clothing display in store, we can change the traditional display forms and realize intelligent display. The store can use multimedia to show consumers the wearing effect of clothes and help consumers to predict their own wearing effect, thus save try-on time and accelerate purchasing speed.

Improve the superiority of shopping environment. Consider to place comfortable chairs and arrange tea and other intimate service for consumers and their accompanies, 
so that they are willing to try on clothes in the store repeatedly. In this way, the purchase rate may be increased.

\section{E. Strengthening the network integration}

In the new situation, it is not wise for operators to use a single marketing model. Operators can integrates the marketing means and supply the deficiencies to solve the current marketing problems. Through previous analysis, we can see that both store and the online shop have advantages and disadvantages. However, they can complement each other and achieve win-win results on the basis of their own advantages. For example, the clothing store can advertise its clothing through internet and promote try-on experience of consumers in order to avoid the defect of online shopping that consumers can not try it on. At same time, operators can establish an online purchasing platform to facilitate the purchase of consumer. In this case, the operators of the store can harvest two sources of customers. The customers receiving good service experience in store can also make a verbal propaganda to promote the sale of the network. If operators integrate the two channels and supply their deficiency, they can meet the needs of consumers in a comprehensive way.

\section{CONCLUSION}

The research results of this paper are aimed to promote the update of the marketing idea of clothing store under the impact of network marketing. Therefore, we can use the advantages of the store and create the marketing model that is conducive to the development of the industry, improve efficiency, and make the clothing retail industry gain a firm foothold in the consumer market. At same time, it also has a certain impact and guidance role in current network clothing marketing model. We can learn both of their advantages and effectively integrates the two marketing models, and constantly explore new marketing model to adapt to the development of the times.

In short, the clothing store can't completely throw itself into network marketing and shut because of the impact of online shop. Although the store is a traditional thing and ecommerce is emerging thing, they interplay and are indispensable. What we need to do is to find a balance between them and supply their deficiency, rely on and develop both of them together, so that the conflicts would be eliminated in the competition. As a consequence, the clothing business and consumer market can operate in a healthy way.

\section{REFERENCES}

[1] Zhang Xiaoqian. Clothing E-commerce, Beijing: China Textile Press, 2007.

[2] Tian Jie et al. Electronic Commerce: Model System and its Operation, Beijing: Communication University of China Press, 2009.

[3] Schneider (US). Electronic Commerce, Beijing: Mechanical Industry Press, 2013.

[4] Wu Aili et al. Collection of Clothing Display Design in Store. Beijing, Chemical Industry Press, 2013.
Jiang Zhiwei et al. A Case Book of Fashion Brand Marketing. Shanghai, Donghua University Press, 2008. 